\title{
DEUTSCHE UND SLOWENISCHE PRESSENACHRICHTEN IM ZWEITEN WELTKRIEG AUF SLOWENISCHEM GEBIET
}

\section{Einleitung}

Bekanntlich haben in den Massenmedien (also auch in Zeitungen) veröffentlichte Texte unterschiedliche Funktionen. Verschiedene Autoren führen diese unterschiedlichen Funktionen, bzw. deren divergierende Häufigkeit auf. Die Fachliteratur plaziert an vorderster Stelle Texte mit Benachrichtigungs- bzw. Informationscharakter (betreffend Ereignisse und Personen) (Dular 1974: 68-69, 1979: 54-56, Dular et all 1981: 50-51, Košir 1988: 14); es folgen Texte, die den Adressaten überzeugen (Dular et all 1981: 54) bzw. die (öffentliche) Meinung bilden wollen (Košir 1988: 14), und schließlich erzieherische (Dular 1974: 68, Dular et all 1981: 54, Košir 1988: 14) und unterhaltende Texte (Dular 1974: 68, Košir 1988: 14). Natürlich treten nicht sämtliche Funktionen in jedem Text auf, zumindest nicht im gleichen Verhältnis, sie sind vielmehr ineinander verwoben, wobei eine dieser Funktionen dominiert.

1.1 Sowohl in der deutschen als auch der slowenischen Fachliteratur (um nur zwei Beispiele zu nennen: Lüger 1995, Košir 1988) gilt die Textklasse der informationsbetonten Texte als jene, die bei einer Zeitung - und in den Medien überhaupt - neben der Textklasse mit meinungsbildendem bzw. interpretativem ${ }^{1}$ Charakter die eigentliche Grundaufgabe übernimmt (Lüger 1995: 70), d.h. über die aktuellen Geschehnisse berichtet, während Texte aus der Meinungs- oder Interpretationsklasse gegenüber diesen Geschehnissen eine bewertende Haltung einnehmen. ${ }^{2}$

1 Vgl. Košir (1988: 63): "Beim Lesen von Journalistentexten in der Zeitung stellt man bald fest, daß diese zuerst einmal in zwei große Gruppen aufgeteilt werden können. Die eine Gruppe /der Journalistentexte in Zeitungen/ setzt sich aus journalistischen Beiträgen zusammen, die den Anschein (unterstrichen von Košir) von objektiven Texten erwecken, in denen der Autor mit der eigenen Meinung nicht anwesend ist. Die zweite große Gruppe setzt sich aus Texten zusammen, die den Anschein (unterstrichen von Košir) von subjektiven Reports vermitteln; der Autor nimmt zum behandelten Thema eine engagierte Haltung ein und ist mit seiner Meinung im Text anwesend. Wir sehen also, daß die Intention des Autors, seine Absicht, die Art, wie der Adressat den Report zu verstehen (zu lesen) hat, im ersten Fall mit informativer Funktion und im zweiten Fall mit interpretativer Funktion verwirklicht wurde. /.../ demzufolge können wir alle beständigen Formen von journalistischer Berichterstattung, in denen konkrete journalistische Texte realisiert werden, in folgende zwei Hauptgruppen oder "Großfamilien" aufteilen: I. Die informative Textklasse und II. Die interpretative Textklasse."

2 Lüger (1995: $66 \mathrm{ff}$ ) unterscheidet zwischen fünf Gruppen von Pressetexten: informationsbetonte Texte, meinungsbetonte Texte, instruierend-anweisende Texte und kontaktorientierte Texte. 
Für informierende Texte ist charakteristisch, daß deren Verfasser dem Leser den Sachverhalt vermittelt (vgl. Lüger 1995: 67: "Der Absender informiert den Adressaten darüber, daß p."), da er darauf abzielt, das mangelhafte Wissen des Adressaten zu verändern/zu vervollständigen. Dabei wird der Sachverhalt (d.h. Ereignisse, Vorgänge u.ä.) nicht bewertet. ${ }^{3}$ Der Adressat/Empfänger nimmt die Informationen zur Kenntnis und hält alles Mitgeteilte für wahrheitsgetreu.

1.2 Die beiden Grundtypen von informationsbetonten Texten sind die "Nachricht" und der "Bericht". ${ }^{4}$

Werfen wir einen Blick darauf, was in der Fachliteratur zu diesen beiden Textsorten steht. Die "Nachricht" ist die elementarste Textsorte bei der informationsbetonten Textklasse. Der Textverfasser berichtet dem Adressaten, daß sich ein Ereignis zugetragen hat (seltener, daß es sich zutragen wird), daß ein gewisser Zustand eingetreten ist/eintreten wird (vgl. Košir 1988: 68); für den Adressaten ist nur das Resultat interessant (Košir 1988: 74), "was zählt, sind Fakten, nicht Zusammenhänge oder Hintergründe" (Lüger 1995: 91) u.ä. Deswegen ist die "Nachricht" äußerst kurz. Da die "Nachricht" zur informationsbetonten Textklasse gehört, sind bei ihr natürlich keine Bewertungen des Textverfassers betreffend der Ereignisse bzw. Zustände u.ä. zu finden. Der Autor ist hier nicht anwesend, seine Haltung ist neutral (Košir 1988: 72).

Der "Bericht" ist umfassender als die "Nachricht", da es sich hier im Gegensatz zur "Nachricht" nicht nur um das Registrieren eines Ereignisses handelt, sondern um die Vorstellung des Ereignisverlaufs (Košir 1988: 73); kurzum, dem Adressaten/ Empfänger soll ein ganzheitlicheres Bild des Ereignisses vermittelt werden (Košir 1988: 74), was also auch ein chronologisches Schildern des Ereignisses beinhaltet (Lüger 1995: 111). Der Autor ist hier ebensowenig anwesend; zumeist ist er ein neutraler Beobachter des Geschehens (Košir 1988: 77).

\section{Forschungsmaterial}

Wie schon der Titel meines Beitrags besagt, waren Gegenstand meiner Forschung Texte, die während des 2. Weltkriegs (genauer gesagt: von 1941 bis 1945) auf

3 Manche behaupten, daß fast jeder Text irgendwie auch Bewertungen einflicht (Hindelang/ Viehweger 1991: 149).

4 An dieser Stelle möchte ich erwähnen, daß sich die von verschiedenen Autoren angewandte Terminologie ziemlich unterscheidet. In der deutschen Literatur trifft man auf die Ausdruicke "Nachricht" (vgl. Lüger 1995: 95, der zwei mögliche Wortbedeutungen anführt: es kann sich 1. um eine Neuheit, eine neue Information, oder 2. um eine journalistische Textsorte handeln), "harte Nachricht", "Meldung" (laut Lüger 1995: 89 die allerkürzeste Sorte, die sogar aus nur einer Äußerung bestehen kann), während in der slowenischen Literatur der Ausdruck "vest" (slowenisch für "Nachricht", z.B. Košir 1988: 72: "hard news" = "kratka vest"). In diesem Artikel werden die Ausdrücke "Nachricht" ("vest") und "Bericht"/"poročilo" verwendet. 
slowenischem Territorium entstanden. Alle wurden in den Zeitungen jener Zeit veröffentlicht, und zwar hauptsächlich auf der Titelseite der Zeitung. Es handelt sich nämlich um Texte, die den feindlichen Kriegsparteien zuzuschreiben sind: einerseits Texte, die im sog. Volksbefreiungskampf (Korpus NOB) entstanden, und andererseits Texte, die von Deutschen geschrieben und (wahrscheinlich) von Slowenen in deutschem Dienst (schlecht) ins Slowenische übersetzt wurden oder von mit den Deutschen sympathisierenden Slowenen in slowenischer Sprache verfaßt wurden (Korpus NEM).

Die Texte des Korpus NOB wurden in zahlreichen (illegalen) Zeitungen und Zeitschriften veröffentlicht, z.B. in Slovenski poročevalec, Partizanski dnevnik, Mladina, wohingegen Texte des Korpus NEM in der Zeitung Karawanken-Boten, der von den Deutschen in Südkärnten, d.h. in Gorenjska/Oberkrain, herausgegeben wurde; die Zeitung hatte ihren Sitz in Klagenfurt und erschien in den Jahren 1941 bis Ende Januar 1945 als halbwöchentliche Zeitung. 5

Die Zeitungen beider Seiten waren für die slowenische Bevölkerung gedacht. Dabei ist anzumerken, daß die Autoren anonym blieben. ${ }^{6}$ In beiden Korpora sind Texte vorzufinden, die nicht von Journalisten verfaßt wurden, sondern von gewissen Institutionen (z.B. Das Oberkommando der Wehrmacht verkündet am 9. Juni, NEM 4; Vojno poročilo Vrhovnega štaba NOV in POJ/Kriegsbericht des Obersten Stabes von NOV und POJ/; NOB 5; Dnevno poročilo štaba IX. korpusa NOV in POJ za 31. 1.45 /Tagesbericht des Stabes des IX. Korpus von NOV und POJ für den 31. 1. 45/; NOB 6), wobei die Texte von den Zeitungen nur veröffentlicht wurden. Im ersten Fall handelt es sich um Informationen über internationale Kriegsschauplätze, im zweiten bzw. dritten um Ereignisse in Jugoslawien oder der Welt.

\section{Ziel}

In meinem Beitrag möchte ich feststellen,

- ob auch in informationsbetonten Texten eine Werbung für die eigene Seite bzw. von Beeinflussung des Adressaten $\mathrm{zu}$ finden sind. Verständlicherweise treten in Zeitungen (insbesondere im Ausnahmezustand "Krieg") auch appellative Texte auf, wo zweifelsohne eine Beeinflussung stattfindet. Bei informationsbetonten Texten jedoch erwartet der Adressat keine solche Beeinflussung;

- wie diese Beeinflussung bei informationsbetonten Texten stattfindet;

- ob Unterschiede zwischen den Textkorpora bestehen, bzw. zwischen den verschiedenen Autoren, die den feindlichen Seiten angehören.

5 Für diese Informationen danke ich Herrn F. Benedik aus dem Museum Gorenjski muzej Kranj.

6 Außer in zwei Fällen des Korpus NEM (NEM 3, NEM 5), wo das Kürzel vH steht - falls es sich hier überhaupt um den Autor handelt. 


\section{Zum Begriff Textsorte}

4.1 Der Text wird als Resultat einer absichtlichen, bewußten Aktivität des Textverfassers betrachtet. Das Ziel des Textverfassers bei der Kommunikation ist, die Kenntnisse des Adressaten abzuändern/neue Kenntnisse zu vermitteln, gewisse Handlungsweisen zu verursachen oder auf dessen (emotionelles) Verhältnis zu sich selbst, zum Textverfasser und/oder zum Sachverhalt Einfluß zu nehmen.

Die kommunikationsorientierte Textlinguistik betrachtet den Text als Verwirklichung einer bestimmten Sprechaktstruktur, und zwar auf der Ebene der Illokution sog. Illokutionsstruktur. Wie jede andere Handlung ist auch die sprachliche Handlung strukturiert. Sie ist nicht nur die Summe der einzelnen Sprechakte, sondern ist hierarchisch organisiert. ${ }^{7}$ Die Illokutionsstruktur des Textes drückt die Kette der Sprechakte (welche verschiedenen Typen zugehören kann) und die Relationen zwischen ihnen aus. Ein Sprechakttyp nimmt in dieser Struktur eine bedeutendere Stellung im Vergleich zu den anderen ein (d.h. ist dominant). Es handelt sich um Textsorten, die als Standardmuster "unter den konkreten Situationsbedingungen als geeignet für die betreffende Intentionsverwirklichung angesehen /werden/ und sich als solche im Laufe der Zeit etabliert haben" (Lüger 1995: 77).

Wenn der Verfasser mit dem Adressaten kommuniziert, benutzt er die Sprache als Einfluß- bzw. Handlungsmittel. Und weil die pragmatische Analyse von der Erkenntnis ausgeht, daß Kommunikation Handlung ist, faßt sie die Sprache als Mittel zum Vollziehen von Sprechakten auf.

4.2 Kehren wir zu unseren Textsorten zurück, d.h. zur Nachricht und zum Bericht. Auch die Nachricht und den Bericht kennzeichnet eine besondere Struktur, auf deren Grundlage der Adressat u. a. erkennt, zu welchem Zweck der Autor den Text verfaßt hat.

Die beiden Textsorten verfaßt der Autor mit der Intention, dem Adressaten einen Ausschnitt des Sachverhalts zu zeigen, den dieser noch nicht kennt. Die Illokutionsstruktur der genannten Textsorten beinhaltet nur Sprechakte der "Mitteilung" (Lüger 1995: 91-92), d.h. stellt Äußerungen zum Sachverhalt dar, die er für überprüft hält; diese Äußerungen sind dem Adressaten unbekannt, für ihn jedoch relevant, und es besteht kein Zweifel, daß er ihnen Glauben schenken wird.

Der Sprechakt der "Mitteilung" ist mit Aussagesätzen realisiert und nicht etwa z.B. mit performativen Verben oder anderen lexikalischen Mitteln. Die "Mitteilung" vermittelt die Überzeugung, daß es sich um etwas Wahres handelt; dies wird jedoch nicht sprachlich verwirklicht.

4.2.1 Die "Nachricht" als Realisierung von Sprechakten der "Mitteilung" stellt das Ereignis nach W-Fragen dar: Wichtig ist, daß etwas geschehen ist (WAS ist geschehen), 
WO und WANN es geschehen ist und WER am Ereignis beteiligt war. Die Struktur ist also denkbar einfach (Košir 1988: 71), schablonisiert; all dies kann in einer einzigen Äußerung ausgedrückt werden (die "Nachricht" muß auch wegen des Aktualitätsbezugs kurz sein). Die "Nachricht" kann auch Antworten auf die Frage "weshalb" (Košir 1988: 71) oder "wie" (Lüger 1995: 93) enthalten, muß das aber nicht notwendigerweise (was beide Autoren - Lüger und Košir) betonen.

Auch der "Bericht" besteht aus "Mitteilungen", die bestimmte Informationen liefern. Während die "Nachricht" jedoch sehr kurz ist, werden beim "Bericht" detailliertere Informationen benötigt; der Adressat will genau über den Verlauf der Ereignisse informiert sein. Košir (1988: 74) meint, daß im "Bericht" Antworten auf die Fragen "was, wann und wo etwas geschehen ist und wer die Ereignisse herbeigeführt hat" zu finden sind, während Lüger die Auffassung vertritt, der "Bericht" beinhalte eine Einleitung, in der das Wesentliche gesagt werde, d.h., was sich zugetragen hat, wer beteiligt war und was die Folgen sind, wobei im mittleren Teil die Einzelheiten, d.h. die chronologische Schilderung des Geschehens ("wie das Ereignis verlaufen ist") wiedergegeben werden; "wie einzelne Aspekte des Ereignisses zusammenhängen, welche Folgen das Ereignis hat, in welchen sozialen, historischen, politischen, kulturellen Zusammenhängen das Ereignis steht" (Lüger 1995: 111-112). "Berichte", die alles Angeführte umfassen würden, gab es in unserem Forschungsmaterial nicht, wahrscheinlich wegen der schwierigen/unvorteilhaften Bedingungen für ein vertieftes Schreiben, so daß für uns v.a. die Information interessant ist, daß das Geschehen chronologisch wiedergegeben wird.

\section{Analyse}

5.1 Die Realisierung der Textsorte in den analysierten Texten

a) Wir können sagen, daß die analysierten Texte zur Textsorte "Nachricht" gehören (z.B. NEM 1), in Ausnahmefällen zum "Bericht" (z.B. NOB 1), was durch eine chronologische Schilderung der Geschehnisse gekennzeichnet ist. "Berichte" sind nur im Korpus von NOB zu finden - bei erfolgreich abgeschlossenem Einsatz, versteht sich.

\section{Velik poraz komunistov pri Žireh}

Poraz pri bitki med Nemci in domobranci na eni strani ter med Vojkovo komunistično brigado pri Žireh, je bil kakor poroča torkov Slovenec, naravnost velik. Komunističnih mrličev so po končani bitki našteli 111. Zaplenjeno je bilo veliko orožja, med tem več strojnic in mnogo pušk. To je zdaj že drugi poraz, ki so ga komunisti doživeli v okolici Logatca. Pri prvem je bil uničen cel bataljon, pri drugem pa izgube komunistov niso nič manjše. Pri tem porazu je bilo tudi ujetih šest komunistov. Med temi šestimi pa so tudi trije znani zločinci: /.../(NEM 1) 


\section{Große Niederlage der Kommunisten bei Žiri ${ }^{8}$}

Die Niederlage in der Schlacht bei Žiri zwischen Deutschen und Heimatkämpfern auf der einen Seite und Vojkos kommunistischer Brigade auf der anderen war - wie die Zeitung "Slovenec" berichtet, geradezu niederschmetternd. Es wurden 111 Kommunistenleichen gezählt. Darüber hinaus wurden viele Waffen, darunter mehrere Maschinengewehre und zahlreiche Gewehre, erbeutet. Das ist jetzt schon die zweite Niederlage, die die Kommunisten in der Umgebung von Logatec erlebten. Bei der ersten wurde ein ganzes Bataillon vernichtet, und auch beim zweiten waren die Verluste der Kommunisten nicht geringer. Bei dieser Niederlage wurden auch sechs Kommunisten gefangengenommen. Unter den sechs befinden sich auch drei bekannte Verbrecher: /.../

\section{Nova borba - uspeh Bazoviške}

Dne 12. septembra so edinice Bazoviške brigade napadle na cesti nad Šempasem nemško vojaško kolono, ki oskrbuje postojanki v Ajdovščini in Vipavi. Kolona je štela okrog 40 vozil. Napad naše vojske je bil odličen. Kolona se je popolnoma razbila. Šele čez nekaj časa so si toliko opomogli, da so nudili odpor. Popoldne sta jim prišla iz Gorice na pomoč dva velika tanka. Svojo akcijo sta tanka usmerila predvsem proti civilnemu prebivalstvu, ter sta v Oseku poškodoval/al 6 poslopij.

Borba je trajala od 9 dopoldne do 6 zvečer. Točnega števila nemških žrtev še nismo ugotovili, morajo biti precejšnje. Naši so uničili 3 kamione, 1 so zasegli nepoškodovanega, mnogo pa je bilo poškodovanih. (NOB 1)

Neues Gefecht - Bazovica-Einheit siegt

Am 12. September haben Einzeltruppen der Brigade von Bazovica auf der Straße oberhalb von Šempas die deutsche Armeekolonne, welche den Stützpunkt in Ajdovščina und Vipava versorgt, angegriffen. Die Kolonne bestand aus ca. 40 Fahrzeugen. Der Angriff unserer Armee war ausgezeichnet. Die Kolonne wurde vollständig zerschlagen. Erst nach geraumer Zeit hatte sie sich so erholt, daß sie Widerstand leisten konnte. Am Nachmittag kamen ihr zwei große Panzer aus Görz zu Hilfe. Ihre Aktion richteten die Panzer v.a. gegen die Zivilbevölkerung und beschädigten in Osek 6 Gebäude.

Der Kampf dauerte von 9 Uhr vormittags bis 6 Uhr abends. Die genaue Anzahl der deutschen Opfer konnte noch nicht ermittelt werden; sie muß beträchtlich sein. Die unsrigen haben 3 Lastwagen zerstört und einen unbeschädigt in Beschlag genommen, viele wurden beschädigt.

Schon vorher wurde erwähnt, daß in beiden Korpora Texte anzutreffen sind, die von einer bestimmten Institution verfaßt und von Zeitungen lediglich veröffentlicht wurden. In solchen Fällen handelt es sich nicht um einen (Zeitungs-) "Bericht", sondern um einen amtlichen Bericht über Armeeaktivitäten, d.h. eine Art Anhäufung. von Mitteilungen oder, wie wir im folgenden noch sehen werden, ein Aufzählen der eigenen Erfolge und der Mißerfolge des Feindes während einer gewissen Zeitspanne, z.B. eines Tages/einer Woche usw. (z.B. NEM 2 und NOB 2). 
Rdeča Armada bije sovražnika

Napredovanje pri Varšavi. RA prekoračila južne Karpate. Nemške izgube

RA je prebila močno utrjene nemške položaje severovzhodno od Varšave, osvobodila preko 100 krajev in ujela 4.000 Nemcev. Na južnem delu vzhodnega bojišča pa je RA prekoračila južne Karpate in osvobodila važno prometno križišče Brasov. V centralni Romuniji je RA uničila grupo nemških vojakov, ki so se skušali prebiti proti zapadu. Ujetih je bilo 3.500 nemških vojakov in 1 general. $V$ čistilnih akcijah ob Donavi je bilo ujetih 5.000 Nemcev, med njimi 18 polkovnikov. Del teh čet je bil prepeljan iz Bolgarije. (NOB 2)

Die Rote Armee bekämpft den Feind

Vorrücken bei Warschau. Die RA hat die südlichen Karpaten überschritten. Deutsche Verluste

Die RA hat die stark befestigten deutschen Stellungen nordöstlich von Warschau durchschlagen, über 100 Ortschaften befreit und 4000 Deutsche gefangen. Im Südteil des östlichen Kampfschauplatzes hat die RA die südlichen Karpaten überschritten und den wichtigen Verkehrsknotenpunkt Brasov befreit. In Zentralrumänien hat die RA eine Gruppe von deutschen Soldaten, die sich nach Westen durchschlagen wollte, vernichtet. Es wurden 3500 deutsche Soldaten und 1 General gefangengenommen. In Säuberungsaktionen entlang der Donau wurden 5000 Deutsche gefangengenommen, darunter 18 Oberste. Ein Teil dieser Truppen war aus Bulgarien herantransportiert worden.

\section{Uspešno napredovanje v trdnjavi Stalingrad}

Od 15. septembra smo uničili 91 oklopnjakov - V 2 dneh smo sestrelili 146 letal

Oberkommando der Wehrmacht je dne 18. septembra objavilo:

Ob Tereku so nemške skupine oklopnjakov, ki so jih podpirala rušilna letala, z obkoljevalnim napadom uničile maso dveh sovražnih bataljonov in uplenile 41 topov.

$V$ boju za Stalingrad smo v srditih bojih v ozkem sodelovanju med vojsko in letalstvom dosegli nadaljnje uspehe.

Ponovne sovražnikove napade proti mostǐ̌ču pri Voronešu smo odbili z velikimi izgubami sovražnika. Od 15. septembra smo v tem prostoru uničili 91 sovjetskih oklopnjakov. Napadi zračnega orožja so bili naperjeni proti sovražnim letališčm $v$ njegovem ozadju.

Južnovzhodno od Ilmenskega jezera in južno od jezera Ladoga so se z izrednimi zgubami zrušili ponovni krajevni napadi močnejših sovražnih sil.

Sovjetsko zračno orožje je 16. in 17. septembra zgubilo 146 letal. Šest lastnih letal pogrešamo. Cilj podnevnih in nočnih napadov nemških bojnih letal so bile v vojni važne naprave na južnem in vzhodnem Angleškem. $V$ Rokavskem prelivu je bil z bombnim zadetkom potopljen nek britanski predstražni čoln. Pomorsko topništvo je sestrelilo dva britanska letala. (NEM 2)

Erfolgreiches Vorrücken in der Festung von Stalingrad

Seit dem 15. September haben wir 91 Panzerfahrzeuge vernichtet - Innerhalb von 2 Tagen haben wir 146 Flugzeuge abgeschossen

Das Oberkommando der Wehrmacht teilte am 18. September mit:

Entlang des Terek haben deutsche Panzerverbände unterstützt von Kampfflugzeugen in einem Umzingelungsangriff zwei feindliche Bataillone radikal vernichtet und 41 Kanonen erbeutet.

In der Schlacht um Stalingrad haben wir in erbitterten Gefechten in enger Kooperation mit Armee und Flugwaffe weitere Erfolge erzielt.

Die erneuten feindlichen Angriffe am Brückenkopf bei Voronesch wurden abgewehrt, wobei der Feind erhebliche Verluste erlitt. Seit dem 15. September haben wir in diesem Raum 91 sowjetische Panzerfahrzeuge vernichtet. Unsere Luftwaffenangriffe richteten sich gegen 
feindliche Flugplätze im Hinterland.

Südöstlich des Ilmenski-Sees und südlich des Ladoga-Sees sind unter erheblichen Verlusten erneute Ortsangriffe stärkerer feindlichen Verbände zusammengebrochen.

Die Sowjetische Luftwaffe verlor am 16. und 17. September 146 Flugzeuge. Unsere Seite vermißt sechs Flugzeuge.

Ziel der Tages- und Nachtangriffe durch deutsche Kampfflugzeuge waren kriegswichtige Anlagen in Süd- und Westengland. Im Ärmelkanal wurde ein Boot der britischen Vorhut mit einem Bombentreffer versenkt. Die Marineartillerie hat zwei britische Flugzeuge abgeschossen.

b) Selten finden sich in den Texten neben dem Sprechakt der "Mitteilung" auch "zusätzliche" Sprechakte, die am Ende des Textes nachgetragen sind und der Erfolgssicherung des dominanten Sprechakts, d.h. des damit verbundenen Ziels, dienen. Sie versuchen, den Leser zu "ïberzeugen", dem Gesagten Glauben zu schenken. Es handelt sich um die Sprechakte des "Lobs" (NOB 3) und des "Aufrufs" (NEM 3).

Štab II. grupe odredov izreka pohvalo 3. četi drugega bataljona za hrabro ponašanje, ker se je $z$ orožjem vred rešila iz brezupne obkolitve in zadala sovražniku težke udarce. (NOB 3)

Der Stab des Gruppenkommandos II. spricht der 3. Truppe des 2. Bataillons sein Lob für besondere Tapferkeit aus, weil sie sich mitsamt ihrer Waffen aus einer hoffnungslosen Umzingelung befreit und dem Feind schwere Schläge versetzt hat.

Sveta dolžnost vseh pametnih Gorenjcev pa je, da se ne samo ločijo od banditskih svetoskruncev in sovražnikov naroda, ampak da se tudi aktivno in javno bojujejo zoper njo, dokler ne bodo ti banditi docela iztrebljeni. Domobranci so jim $k$ temu pokazali pot. (NEM 3)

Es ist die heilige Pflicht aller gescheiten Oberkrainer, sich von den frevlerischen Banditen und Volksfeinden zu trennen - und den aktiven Kampf gegen diese anzutreten, bis sie völlig ausgerottet sind. Die Heimatkämpfer haben uns dazu den Weg gezeigt.

c) Alle behandelten Texte sind thematisch eindeutig: es handelt sich um Texte, die über Kriegsereignisse, d.h. Kämpfe, berichten. ${ }^{9}$ Charakteristisch ist hier, daß der Berichterstatter eine Selektion der Information vornimmt. Betrachten wir das Beispiel der "Nachricht" aus dem Korpus von NEM (siehe oben NEM 1) sowie des "Berichts" aus dem Korpus NOB (siehe oben NOB 1).

Während im Text NOB 1 genau gesagt wird, WAS geschehen ist (vgl./"naši"/ napadli sovražnika - /"unsere" Soldaten/ griffen den Feind an; kolona se je popolnoma razbila - Kolonne wurde vollständig zerschlagen; Točnega števila nemških žrtev še nismo ugotovili, morajo pa biti precejšnje. Naši so uničili 3 kamione, 1 so zasegli nepoškodovanega, mnogo pa jih je bilo poškodovanih. - Genaue Anzahl deutscher Opfer unbekannt, muß aber beträchtlich sein. Die unsrigen haben drei Lastwagen zerstört und einen unbeschädigt in Beschlag genommen, viele wurden beschädigt.),

9 Es ist zu erwähnen, daß sich die Korpora von NEM und NOB darin unterscheiden, daß der Korpus von NEM äußerst wenig Texte beinhaltet, die den Leser direkt über Konfrontationen/Kämpfe zwischen Deutschen und Partisanen in Slowenien informieren würden. Die Deutschen vermeiden Berichterstattungen über Kämpfe in der näheren Umgebung (auf slowenischem Gebiet), während sich die Partisanen gerne damit brüsten - wenn sie siegreich waren, versteht sich. 
WANN es geschehen ist (vgl. 12. 9. 1944 od 9. dopoldne do 6. zvečer - am 12. 9. 1944 von 9 Uhr vormittags bis $6 \mathrm{Uhr}$ abends) und WO es geschehen ist (vgl. na cesti nad Šempasem - auf der Straße über Šempas), wird im Text NEM 1 nur sehr allgemein angeführt, WAS geschehen ist (bitka s porazom nasprotnika - Kampf endete mit Niederlage des Feindes, der schwere Verluste an Mensch und Material erlitt /vgl. 111 komunističnih mrličev - 111 kommunistische Leichen; ujetih 6 komunistov, med njimi znani zločinci - 6 gefangene Kommunisten, darunter berüchtigte Verbrecher; zaplenjeno veliko orožja, več strojnic in mnogo pušk - viele Waffen, mehrere Maschinengewehre und viele Pistolen erbeutet), WO (vgl. pri Žireh - bei Žiri) und WANN (nur das Erscheinungsdatum der Zeitung ist angegeben; der Kampf fand am Vortag oder vor einigen Tagen statt) es geschehen ist. Darüber, WER die Teilnehmer des Geschehens bzw. Kampfs, waren, erfahren wir im Text aus dem Korpus von NEM lediglich für die deutsche Seite (vgl. allgemein Nemci in domobranci - Deutsche und Heimatkämpfer); die feindliche Seite wird von den Deutschen exakt, obwohl auf "journalistische" Art nach dem Anführer benannt (vgl. Vojkova komunistična brigadaVojkos kommunistische Brigade). Dahingegen führt der Schreiber des NOB-Textes den Namen seiner Einheit im Detail an (vgl. edinice Bazoviške brigade - Einzeltruppen der Brigade von Basovizza), der Gegner jedoch nur mit nemška vojaška kolona (40 vozil) deutsche Armeekolonne (40 Fahrzeuge); erwähnt wird auch die Bewaffnung: dva velika tanka - zwei große Panzer.

Ich möchte hier noch erwähnen, daß der Autor mit der Äußerung Der Angriff unserer Armee war ausgezeichnet explizit den Sachverhalt (das Ereignis) bewertet, was für die informationsbetonte Textklasse atypisch ist.

Betrachten wir nun noch andere Texte, wobei wir eine Übersicht der folgenden Daten herstellen wollen.

\section{WAS hat sich ereignet, einschließlich der FOLGEN (Verlust an Mensch und Material)?}

Es ist interessant, daß unter Was ist geschehen? die Folgen eigentlich ganz genau angegeben werden (d.h. der Verlust an Mensch und Material), und zwar immer jeweils mit besonderer Präzision beim Feind. Das hat sich schon in den beiden obenstehenden Beispielen gezeigt (NOB 1, NEM 1). Selten trifft man auf das Beispiel, daß Verluste auf der eigenen Seite angeführt sind, während dies häufig beim Feind zutrifft, und zwar sehr allgemein oder auch präzise (sogar mit Angabe in Zahlen, die wegen des Abrundens fragwürdig scheint). Die Anzahl der Opfer ist beim Feind natürlich immer größer. 


\begin{tabular}{|c|c|c|}
\hline Verlust & Textverfasser über die eigene Seite & Textverfasser über die feindliche Seite \\
\hline - Opfer & & $\begin{array}{l}\text { Die genaue Anzahl der deutschen Opfer konnte } \\
\text { noch nicht ermittelt werden; sie muß } \\
\text { beträchtlich sein. (NOB 1) } \\
\text { Die RA/ hat /.../4000 Deutsche gafangen. } \\
\text { D/ie RA /hat/ eine Gruppe von deutschen } \\
\text { Soldaten /../ vernichtet. } \\
\text { Es wurden } 3500 \text { deutschen Soldaten und } 1 \\
\text { General gefangengenommen. } \\
\text { /../wurden } 5000 \text { Deutsche gefangengenommen, } \\
\text { darunter } 18 \text { Oberste. (NOB } 2) \\
\text { Es wurden } 111 \text { Kommunistenleichen gezählt. } \\
\text { /../wurden auch sechs Kommunisten } \\
\text { gefangengenommen. (NEM } 1) \\
\text { /../zwei feindliche Bataillone radikal vernichtet. } \\
\text { /../ der Feind erhebliche Verluste erlitt. (NEM 2) }\end{array}$ \\
\hline $\begin{array}{c}\text { - materieller } \\
\text { Schaden }\end{array}$ & $\begin{array}{l} \\
\text { Unsere Seite vermißt sechs } \\
\text { Flugzeuge. (NEM 2) }\end{array}$ & 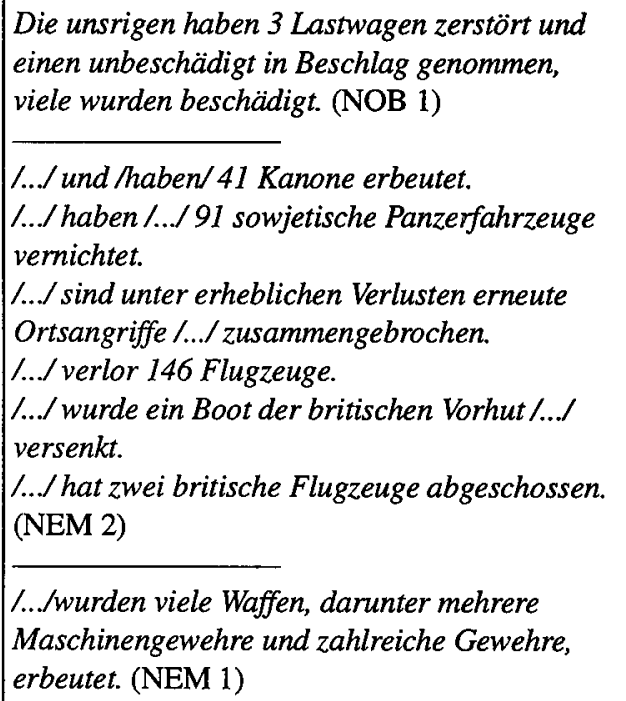 \\
\hline
\end{tabular}

In der Mehrzahl der Fälle legt der Autor die wesentlichen Erfolge seiner Seite schon im Titel dar, während er im Untertitel die Mißerfolge des Gegners anführt, z.B. Uspešno napredovanje $v$ trdnjavi Stalingrad - Erfolgreiches Vorrücken in Festung Stalingrad mit dem Untertitel: Od 15. septembra smo uničili 91 oklopnjakov - V 2 dneh smo sestrelili 146 letal - Seit dem 15. September haben wir 91 Panzerfahrzeuge vernichtet - Innerhalb von 2 Tagen haben wir 146 Flugzeuge abgeschossen (NEM 2) oder Rdeča armada bije nasprotnika - Die Rote Armee schlägt den Feind mit dem Untertitel Napredovanje pri Varšavi. RA prekoračila južne Karpate. Nemške izgube - 
Vorrücken bei Warschau. Die RA hat die südlichen Karpaten überschritten. Deutsche Verluste (NOB 2). In den angeführten Fällen wird das zentrale Thema im Titel zusammengefaßt; der Untertitel führt die Nebenthemen ein.

\section{WO ist es geschehen?}

Die Antwort auf diese Frage ist in allen Texten $\mathrm{zu}$ finden, obwohl ziemlich allgemein (NEM 1, 2 u.a.) oder gar völlig allgemein, vgl. ein gewisses Dorf in der Region Primorska (NOB 4):

$V$ novembru so Nemci nenadoma vdrli v neko vas na Primorskem. Mladinke so pravočasno rešile ranjenega tovariša, ki je ležal v vasi. Iz besa so Nemci zažgali hišo, $v$ kateri je ležal ranjenec in so $v$ njo zaklenili gospodinjo. Toda mladinke so jo rešile iz goreče hiše. (NOB 4)

Im November sind die Deutschen plötzlich in ein gewisses Dorf in der Region Primorska eingedrungen. Junge Mädchen konnten einen verwundeten Genossen, der im Dorf lag, noch rechtzeitig retten. In ihrer Wut steckten die Deutschen das Haus in Brand, in dem der Verwundete lag, und sperrten die Hausherrin mit ein. Dem Mädchen gelang es jedoch, sie aus dem brennenden Haus zu retten.

Nur in einem Fall ist der Ort der Berichterstattung angegeben: Stein, den 15. Dezember (NEM 3), während für mehr Überzeugungskraft beim Leser nur dadurch gesorgt wird, daß als Informationsquelle die höchsten Armeeorgane angegeben werden. Diese Pseudo-Berichte führen den Ort der Kampfhandlungen oberflächlich auf:

\begin{tabular}{|l|l|}
\hline NEM 2 & NOB 2 \\
\hline - entlang der Terek & - nordöstlich von Warschau \\
-/vor/Stalingrad & - im Südteil des östlichen Kampfschauplatzes \\
- am Brückenkopf bei Voronesch & - in Zentralrumänien \\
- südostlich des Ilmenski-Sees & - entlang der Donau \\
südlich des Ladoga-Sees & \\
in Süd- und Westenengland & \\
im Ärmelkanal & \\
\hline
\end{tabular}

\section{WANN ist es geschehen?}

In einigen Texten wird auch das Kampfdatum erwähnt (vgl. am 7. November; NEM 3). Der Leser berücksichtigt natürlich auch das Erscheinungsdatum der Zeitung, weil - wie wir schon sagten - am Anfang des Textes weder Ort noch Entstehungsdatum des Textes angeben werden (mit Ausnahme eines Falls: Stein, den 15. Dezember, NEM 3). Bei den sog. Berichten der Armeeorgane ist das Datum (ev. mehrere) im Text zu finden (siehe NEM 2). 


\section{WER war am Ereignis beteiligt?}

Bei einer detaillierten Schilderung des Ereignisses würde man die Anführung der Namen der auf beiden Seiten kämpfenden Einheiten, die Anzahl der Soldaten, wenn dies nicht sowieso aus der Bezeichnung dem Namen der Einheit hervorgeht - sowie die Art ihrer Bewaffnung - erwarten.

Die Resultate der Analyse sind äußerst interessant: Der Name der eigenen Einheit wird im Korpus von NOB nur einmal angeführt, wobei bemerkenswert ist, daß im Text aus dem Korpus von NEM lediglich der Name der feindlichen Einheit angegeben ist der eigene Name fehlt (NEM 1); im übrigen wird v.a. die Bewaffnung des Gegners angeführt, was den Anschein einer guten Bewaffnung erweckt; wie jedoch in der Folge geschildert wird, erleidet eben diese sehr gut bewaffnete Einheit schwere Verluste (in der Tabelle unten mit * bezeichnet). Ist die Bewaffnung für die eine Seite angegeben, so fehlt sie für die andere.

\begin{tabular}{|c|c|c|}
\hline WER & $\begin{array}{l}\text { Textverfasser über die } \\
\text { eigene Seite }\end{array}$ & Textverfasser über die feindliche Seite \\
\hline \multirow{2}{*}{$\begin{array}{l}\text { Anführung der Namen der } \\
\text { am Kampf beteiligten Trup- } \\
\text { pen }\end{array}$} & \multirow{2}{*}{$\begin{array}{l}\text { Einzeltruppen der Brigade } \\
\text { von Bazovica (NOB 1) }\end{array}$} & \\
\hline & & $\begin{array}{l}\text { Vojkos kommunistischer Brigade (NEM } \\
\text { 1) }\end{array}$ \\
\hline \multirow[t]{2}{*}{$\begin{array}{l}\text { Anzahl der am Kampf } \\
\text { beteiligten Soldaten }\end{array}$} & & 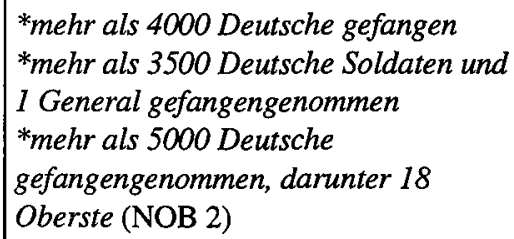 \\
\hline & & $*_{z w e i}$ feindliche Bataillone (NEM 1) \\
\hline
\end{tabular}

\subsection{Realisierung der sprachlichen Mittel}

Die Gewinnung des Adressaten verläuft nicht mit einer gewöhnlichen Struktur, sondern auch/insbesonders direkt mit Auswahl der ungewöhnlichen/nicht neutralen/ expressiven sprachlichen Mittel seitens des Berichterstatters. Es handelt sich um emotionelle Bezeichnungen beider Seiten (d.h. der eigenen und jener des Feindes, bzw. deren Handlungen), z.B. als Bezeichnung der feindlichen Seite: OF-Banditen (NEM 3, NEM 5), frevlerische Banditen (NEM 3), "Befreier" (NEM 3), "Befreier des slowenischen Volkes" (NEM 5), Kommunisten (NEM 1), Faschisten (NOB 7), Lumpenpack (NOB 7), und für die Handlungen des Feindes: frevlerisches Banditenwesen (NEM 3), sowie die feindlichen Opfer: Kommunistenleichen (NEM 1). In institutionalisierten "Berichten" finden sich emotional unbelastete Ausdrücke bzw. weniger emotional geladene Ausdrücke: Sowjets (NEM 4), Feind (NEM 4), faschistische Miliz und Armee (NOB 3), Italiener (NOB 3), Faschist (NOB 3). 
Wenn der Schreiber von den Aktivitäten seiner Seite spricht, verwendet er die erste Person Plural, so als ob er, der Autor, aktiv dazu gehören würde: Wir haben vernichtet wir haben erschossen - wir haben erreicht (NEM 2), der Angriff unserer Armee (NOB 1), unsere Truppe (NOB 3), unsere Kämpfer (NOB ?).

Der Adressat wird folgendermaßen bezeichnet: alle ehrlichen und gläubigen Oberkrainer (NEM 3), alle gescheiten Oberkrainer (NEM 3).

\section{Abschluß}

Die Analyse hat folgendes aufgezeigt:

- Eine Beeinflussung des Adressaten ist auch bei der Nachricht bzw. beim Bericht als informationsbetonter Textsorte zu finden ist, wo dies eigentlich nicht zu erwarten wäre.

- Die Autoren der Texte gewannen den Leser für sich/nahmen auf ihn Einfluß, indem sie nicht nur nicht neutrale/expressive sprachliche Mittel verwendeten besonders bei der emotionell negativen Bezeichnung des Feindes und seiner Handlungen -, sondern auch/inbesondere mit der Strukturierung dieser Texte: es handelt sich um "Nachrichten", in denen v.a. angeführt ist, WAS sich ereignet hat (d.h. was für negative Folgen der Gegner erlitten hat); im wesentlichen fehlen jedoch genaue Angaben darüber, WO und WANN sich das Ereignis abgespielt hat und WER daran beteiligt war.

"Berichte" sind kaum zu finden, und wenn sie als solche bezeichnet werden, so handelt es sich lediglich um Aufzählungen/Anhäufungen von Mitteilungen. Es muß gesagt werden, daß solche Beiträge nicht vom Autor unterschrieben sind.

- Zwischen den Texten verschiedener Autoren treten keine Unterschiede auf (d.h. im Korpus von NOB und NEM): beide sind dadurch gekennzeichnet, daß eher zu wenig als zu viel gesagt wird (keine Präzision); der Leser kann in Ermangelung genauerer Angaben auch nicht nachprüfen, wie es um die Glaubwürdigkeit eines solchen Textes bestellt ist.

\section{Quellenverzeichnis}

NEM 1 Vesti iz Ljubljane in okolice (Karawanken Bote 26. 1. 1944)

NEM 2 Uspešno napredovanje v trdnjavi Stalingrad (KB 23. 9. 1942)

NEM 3 OF je razstrelila cerkev na Gorenjskem (KB 16. 12. 1944)

NEM 4 Oberkommando der Wehrmacht je dne 9. junija objavilo (KB 12. 6. 1943)

NEM 5 Hud poraz of-arskih banditov (KB 28. 10. 1944)

NOB 1 Nova borba - uspeh Bazoviške (Partizanski dnevnik 17. 9. 1944)

NOB 2 RA bije sovražnika (PD 7.9. 1944) 
NOB 3 Poročila s slovenskih bojišč (Slovenski poročevalec 21. 4. 1942)

NOB 4 Primorska (Mladina konec decembra 1943)

NOB 5 Vojno poročilo Vrhovnega štaba NOV in POJ (PD 4. 2. 1945)

NOB 6 Dnevno poročilo štaba IX. korpusa NOV in POJ za 31. 1. 45 (PD 4. 2. 1945)

NOB 7 Napad na žandarmerijo v Zagorju (Spor 16. 8. 1941)

\title{
Literaturverzeichnis
}

Brandt, M. et all (1983), Der Einfluß der kommunikativen Strategie auf die Textstruktur - dargestellt am Beispiel des Geschäftsbriefes. In: I. Rosengren (Hrsg.), Sprache und Pragmatik, Lunder Symposium 1982, Malmö, S. 105-136.

Hindelang, W., Viehweger, D. (1991), Textlinguistik, Niemeyer Verlag, Tübingen.

Dular, J. (1974), Zvrstnost slovenskega jezika, v: Informativni zbornik SSJLK, Filozofska fakulteta, Ljubljana, 57-74.

Dular, J. et all (1981), Slovenski jezik I, Založba Obzorja, Maribor.

Koch, W., Rosengren, I., Schonebohm, M. (1981), Ein pragmatisch orientiertes Textanalyseprogramm. In: Lunder Germanische Forschungen 50, S. 155-203.

Košir, M. (1988), Nastavki za teorijo novinarskih vrst, Državna založba Slovenije, Ljubljana.

Lüger, H.-H. (1995), Pressesprache, Max Niemeyer Verlag, Tübengen.

Motsch, W., Pasch, R. (1987), Illokutive Handlungen. In: W. Motsch (Hrsg.), Satz, Text, sprachliche Handlung, Studia grammatica XXV, Berlin, S. 11-80.

Motsch, W., Reis, M., Rosengren, I. (1990), Zum Verhältnis von Satz und Text, Deutsche Sprache, Berlin, 97-125.

Viehweger, D. (1983), Sequenzierung von Sprachhandlungen und Prinzipien der Einheitenbildung im Text. In: R. Ružička, W. Motsch (Hrsg.), Untersuchungen zur Semantik, Studia grammatica XXII, Berlin, 369-394.

\author{
Povzetek \\ NEMŠKA IN SLOVENSKA ČASOPISNA BESEDILA MED DRUGO SVETOVNO VOJNO NA \\ SLOVENSKEM OZEMLJU
}

\begin{abstract}
Analiza časopisnih besedil, ki so nastala med 2. svetovno vojno v slovenskem jeziku na slovenskem ozemlju in katerih avtorji so pripadali nasprotnima "stranema" v vojni (korpus NOB /Slovenski poročevalec, Partizanski dnevnik, Mladina/ in korpus NEM /Karawanken Bote/), namenjena pa so bila slovenskemu bralcu, je pokazala, da 1) je najti vplivanje na naslovnika tudi v vesti/poročilu kot informativnih besedilnih vrstah; 2) so avtorji besedil pridobivali bralca/nanj vplivali ne le $\mathrm{z}$ izbiro nenevtralnih/ekspresivnih jezikovnih sredstev, ki se kažejo predvsem $v$ čustveno negativnem poimenovanju nasprotnika in njegovih dejanj, ampak tudi/predvsem $s$ strukturiranostjo teh besedil: navedeno je, kaj se je zgodilo, tj. kakšne posledice je utrpel nasprotnik, v glavnem pa manjkajo točni podatki o tem, kje in kdai se je zgodil dogodek in kdo so bili njegovi udeleženci; 3) ni zaznati razlik med besedili iz korpusa NOB in NEM: za oboje je značilno, da povedo raje manj kot dovolj (avtorji so nenatančni); bralec zaradi tega, ker ima na razpolago premalo podatkov, tudi ne more preveriti verodostojnosti povedanega.
\end{abstract}

